\title{
Old fish in a young lake: stone loach (Pisces: Barbatula barbatula) populations in Lake Constance are genetically isolated by distance
}

\author{
MARTA BARLUENGA and AXEL MEYER \\ Department of Biology, University of Konstanz, Universitätsstrasse 10, 78457 Konstanz, Germany
}

\begin{abstract}
The genetic structure of 10 populations (453 individuals) of stone loach (Barbatula barbatula L.), a small bottom-dwelling cyprinid fish, in the littoral zone of Lake Constance, central Europe, was investigated by analysing the mitochondrial control region sequences and five microsatellite loci. An unexpectedly high degree of genetic diversity (up to $0.36 \%$ ) and old estimated age of these populations ( $>150000$ years) based on mitochondrial DNA (mtDNA) was found. These findings contrast with the relatively young age of the lake, which could be colonized by fish only after the last ice age around $15000 \mathrm{BP}$. Stone loach appears to be an old species in a young lake. Both types of molecular markers showed population genetic structure pronounced in mtDNA (overall $F_{\mathrm{ST}}=0.15$ ) but moderate in microsatellites $\left(F_{\mathrm{ST}}=0.03\right)$. As predicted by its life history, philopatry, and limited capacity for dispersal, stone loach populations of Lake Constance show a clear pattern of isolation by distance. Geographic distances along the shores are the best explanation for the observed geographical distribution of genetic differentiation $(r=0.88)$, indicating that open water represents a barrier for the dispersal of the stone loach. The colonization of Lake Constance might have occurred initially at one location and then populations spread throughout the lake in a stepwise manner following the shoreline, and subsequently remained largely genetically isolated as suggested by the large observed differences among them.
\end{abstract}

Keywords: bottom-dwelling fish, cyprinid fish, dispersal, isolation by distance, microsatellites, mitochondrial control region

Received 11 August 2004; revision received 7 December 2004; accepted 7 December 2004

\section{Introduction}

The populations of most, if not all, species show some levels of genetic structuring. Analyses of the genetic population structure in many fish species revealed that individuals from different areas of a lake are typically genetically substructured into different local populations (e.g. Brunner et al. 1998; Douglas et al. 1999; Garant et al. 2000; Gerlach et al. 2001). Even the European eel (Anguilla anguilla), often considered the classic example of a randomly mating (panmictic) population, because all individuals migrate to a common reproduction site in the

Correspondance: Axel Meyer, Fax: + 49-7531-883018; E-mail: axel.meyer@uni-konstanz.de
Sargasso Sea, has recently been shown to be geographically structured (Wirth \& Bernatchez 2001). Genetic differentiation of local populations is caused, among other reasons, by environmental barriers and limited dispersal (e.g. Johnson \& Gaines 1990), which restrict migration and therefore limit gene flow.

The stone loach Barbatula barbatula L., 1758 is a small bottom-dwelling cyprinid fish, widely distributed in Eurasian freshwater habitats, common in shallow, fastflowing creeks, but also found in shallow areas of clear lakes (Muus \& Dahlström 1968). It requires rocky substrates and high levels of oxygen - making it sensitive to pollution (Wheeler 1992). Stone loach is supposed to be a poor disperser, a character that together with its small size (max. 12-13 cm; Smyly 1955) and short lifespan (max. 5 years; Mills et al. 1983) might have important effects on 
the population substructure of its populations. Therefore, the stone loach appears to be an excellent model species for the study of population substructuring in a temperate environment. Its life history and biology predicts that the basic process shaping the population genetic structure of its populations might follow a model of isolation by distance. Fine-scale population structure studies of freshwater fish species are relatively scarce for temperate areas (but see e.g. Koskinen et al. 2001; Castric \& Bernatchez 2003) but numerous ones have been conducted for populations in tropical zones, in particular in cichlid fishes. In this group of fishes, the use of rock-dwelling habits is often correlated to strong genetic subdivision and high levels of speciation (Van Oppen et al. 1997; Arnegard et al. 1999; Markert et al. 1999; Rico \& Turner 2002; Taylor et al. 2001a).

Here, we report on a study of the fine-scale population genetic structure of stone loach in the littoral area of Lake Constance, central Europe. This lake is the second largest pre-Alpine lake in Europe $\left(571.5 \mathrm{~km}^{2}\right)$ and was formed by the Rhine glacier proceeding from the inner Alps, on the border between Western and Eastern Alps. The earliest colonization of this lake by fish might have taken place during the retreat of the most recent glacier 10 000-15 000 вP (see Behrmann-Godel et al. 2004). The basins of the Danube and Rhine rivers are thought to have acted as the most important refugia for freshwater fish in this area during the most recent ice age (e.g. Nesbø et al. 1999; Weiss et al. 2002; Salzburger et al. 2003). Lake Constance is a deep lake (mean depth $=95 \mathrm{~m}$; max. depth = $254 \mathrm{~m}$ ), rather heterogeneous with alternation of deep and shallow areas, and rocky, sandy and muddy stretches (Fischer \& Eckmann 1997a). In the lake, the stone loach is confined to the littoral zone during its entire lifespan where it inhabits stony-gravel areas hiding in rocky crevices for shelter (Fischer \& Eckmann 1997b).

Probably because of the lack of economic interest in the stone loach, knowledge about this small species is somewhat limited. Many aspects of its biology still remain unknown, such as details about its spawning behaviour, basic physiology, and its ability for dispersal. The stone loach is an ideal species for the study of the genetic consequences of a rock-dwelling lifestyle because, unlike most other European freshwater fish species, there is no evidence for human induced faunal translocations in this species (it was, however, introduced between 1600 and 1700 to Ireland; Wheeler 1992). Therefore, the current distribution of genetic variation within and among populations of the stone loach in Lake Constance is expected to reflect its natural geographical and population genetic history.

We used sequences of the mitochondrial DNA (mtDNA) control region and five microsatellite markers to study the fine-scale population structure of several populations of the stone loach in Lake Constance. We focused on two main questions: the colonization history of stone loach in
Lake Constance, and the genetic differentiation between different populations distributed in the littoral zone of the lake. More specifically, we tested whether isolation by distance, defined as the increase of genetic differences with geographical distance (Wright 1943), is the basic process shaping the structure of stone loach populations. Lastly, we discussed the consequences of the patchy distribution habitat-bound populations on the evolution and the potential for speciation of stone loach populations.

\section{Materials and methods}

\section{Sample collection}

Stone loach specimens were collected during two different seasons (December and June) for two consecutive years (December 2001, June 2002, December 2002, June 2003) from 13 localities with stony-gravel substrate of the littoral zone (1-100 cm water depth) of Lake Constance. Fish were collected at 11 sites, separated by a regular distance of $c .4 \mathrm{~km}$, along the shoreline of the northwestern part, called Lake Überlingen, of Lake Constance (sites 1-11; Fig. 1a). Because this part of the lake contains a very deep zone and a relatively narrow stretch, it appears ideal to test the ability of the stone loach to cross profundal areas by looking at the genetic structure of its populations. Two localities in the northeastern part of the lake (upper lake, sites 12 and 13; Fig. 1a) were also sampled as a 'geographical control' of genetic diversity. Stone loach was entirely absent or occurred in extremely low abundance in three of those localities (sites 3, 5 and 7; see Table 1) and, hence, only 10 of the 13 sampled localities were included in the study. A maximum of 20 individuals per site for each sampling campaign were captured using electric fishing gear. A total of 453 individuals were collected and analysed (see Table 1 for further information). A fin clip was taken from each fish and preserved in $80 \%$ ethanol for laboratory analyses, and fish were released back in the lake.

\section{mtDNA amplification and sequencing}

Total DNA was isolated using a proteinase $\mathrm{K}$ digestion followed by sodium chloride extraction and ethanol precipitation (Bruford et al. 1998). The complete mitochondrial control region (1100 bp) was amplified using published primers and polymerase chain reaction (PCR) conditions (Kocher et al. 1989; Meyer et al. 1994) with a GeneAmp PCR System 9700 Thermocyler (Applied Biosystems). The PCR products were purified using the QIAquick PCR Purification Kit (QIAGEN), and sequenced in both directions with the BigDye Terminator Cycle Sequencing Ready Reaction Kit (Applied Biosystems). Sequencing products were analysed on ABI 3100 Automated Sequencer 


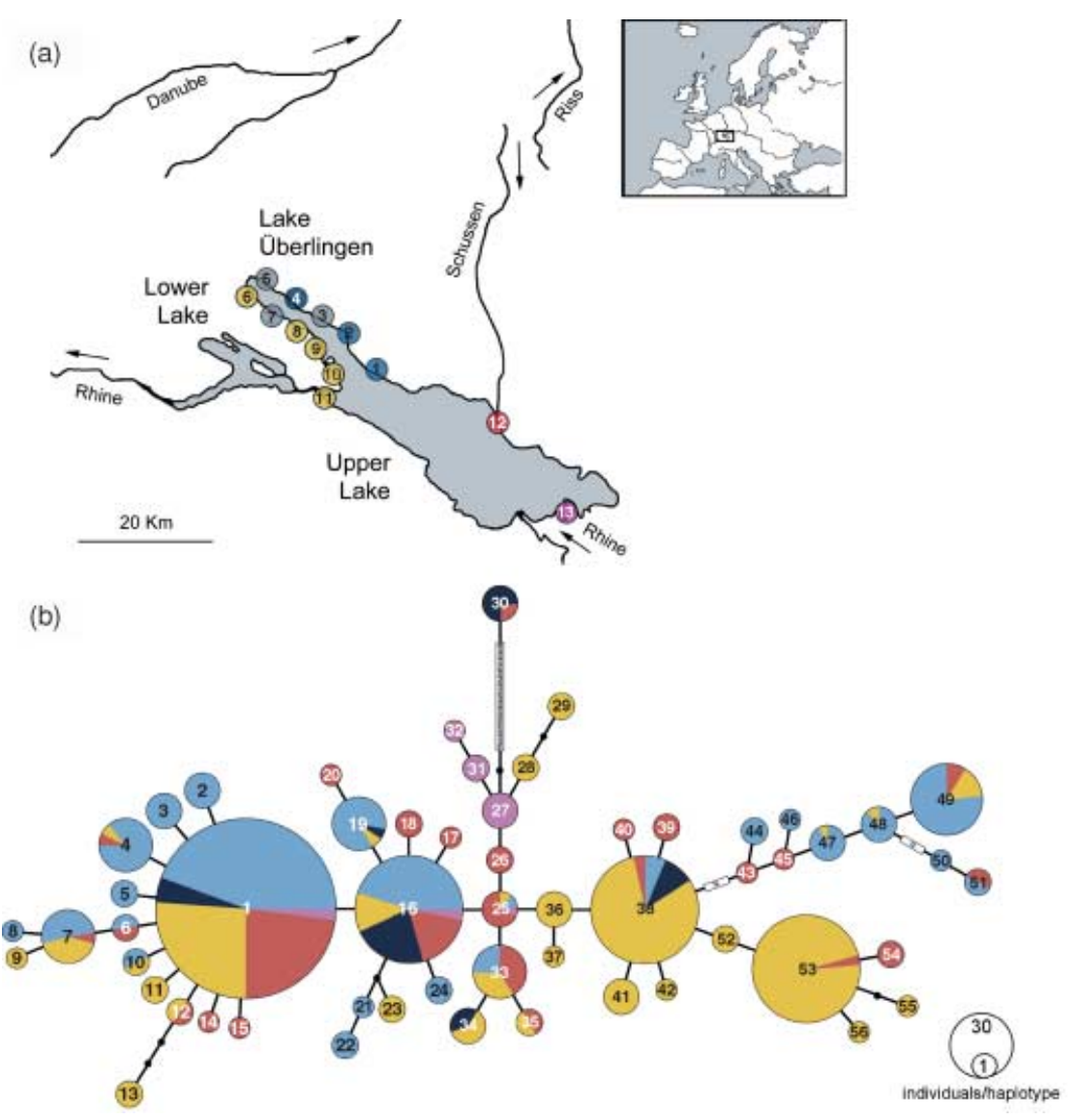

Fig. 1 (a) Map of Lake Constance in central Europe showing the sampling localities. Circles reflect the sampling sites: 1, Meersburg (Meer), 2, Birnau (Bir), 3, Überlingen (Über), 4, Sipplingen (Sipl), 5, Ludwigshafen (Ludw), 6, Bodman (Bod), 7, Marienschlucht (Mari), 8, Klausenhorn (Klaus), 9, Litzelstetten (Litz), 10, University (Uni), 11, Konstanz (Kon), 12, Langenargen (Lang), 13, Austria (Aut). Colors represent the major geographical groups. Localities in grey did not contain samples of stone loach and were not included in the study. (b) Unrooted haplotype network of the mtDNA control region showing the geographical distribution of haplotypes. Haplotypes are coloured according to geographical localities. The sizes of the haplotypes reflect the number of specimens sharing the same haplotype (see scale in the lower right corner).

Table 1 Sample sizes collected per locality and per season and year

\begin{tabular}{|c|c|c|c|c|c|c|c|c|c|c|c|c|c|}
\hline & 1 Meer & $2 \mathrm{Bir}$ & 3 Über & $4 \mathrm{Sipl}$ & $5 \mathrm{Ludw}$ & $6 \mathrm{Bod}$ & 7 Mari & 8 Klaus & 9 Litz & 10 Uni & 11 Kon & 12 Lang & 13 Aut \\
\hline Dec 2001 & 20 & 20 & - & - & - & 20 & - & 0 & - & 14 & 20 & 20 & - \\
\hline Jun 2002 & 20 & 20 & - & - & - & 7 & - & 17 & - & 18 & 14 & 20 & - \\
\hline Dec 2002 & 16 & 16 & 1 & 18 & 0 & 3 & 1 & 7 & 13 & 11 & 20 & - & 6 \\
\hline Jun 2003 & 14 & 10 & 0 & 18 & 0 & 18 & 0 & 8 & 14 & 8 & 13 & - & 10 \\
\hline Total & 70 & 66 & 1 & 36 & 0 & 48 & 1 & 32 & 27 & 51 & 67 & 40 & 16 \\
\hline
\end{tabular}

Numbers of localities are related to Fig. 1a. Names of localities are abbreviated (for complete names see legend in Fig. 1a).

(Applied Biosystems). The mtDNA sequences of this study have been deposited in GenBank under the Accession nos AY833737-AY834171.

\section{Microsatellite analysis}

Five nuclear microsatellite loci were genotyped (Bbar1, Bbar3, Bbar4, Bbar7, Bbar8; Taylor et al. 2001b). Microsatellites were amplified with fluorescent reverse primers (FAM and HEX dyes) and fragment length was analysed with the internal size marker Genescan-500 ROX (Applied Biosystems) on an ABI 3100 Automated Sequencer (Applied Biosystems), and scored with GENOTYPER version 3.7 (Applied Biosystems) software package.

\section{Phylogenetic and statistical analyses}

$m t D N A$ control region. Mitochondrial DNA sequences were aligned by eye and different haplotypes were identified with COLlaPSE version 1.1 (Posada 1999). All haplotypes found were plotted on an unrooted minimumspanning haplotype network (Fig. 1b), according to the optimal tree obtained from a maximum-likelihood analysis in PAUP* version 4.0b10 (Swofford 2002). A model of sequence evolution was chosen using a nested series of likelihood ratio tests (Huelsenbeck \& Crandall 1997) applying modeltest 3.06 (Posada \& Crandall 1998). MODELTEST revealed that the optimal model of molecular evolution for our data set was Tamura and Nei (corrected 


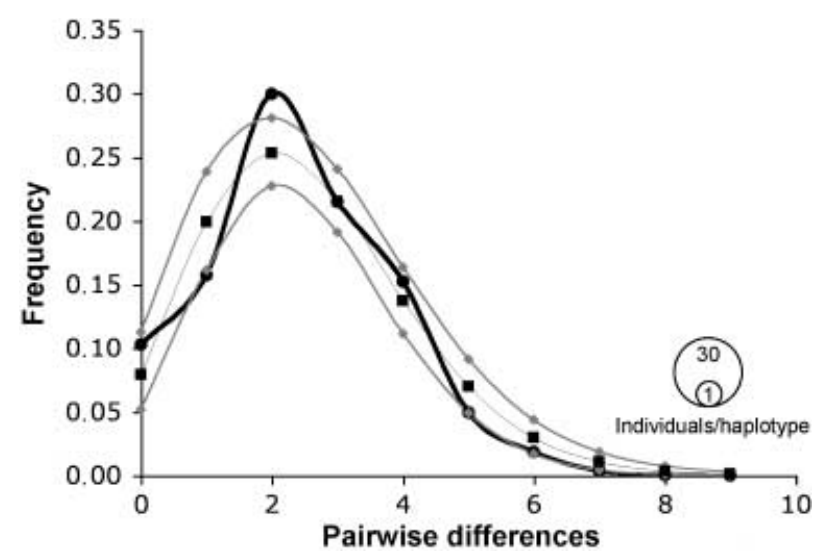

Fig. 2 Frequency distribution of pairwise numbers of mutational differences in mtDNA between stone loach individuals from Lake Constance. The thick black curve represents the observed values, the dashed curve with squares the model fitted to the data, and the dashed upper and lower curves the lower and upper boundaries (1000 simulations).

with a gamma parameter of $\alpha=0.73$ and a proportion of invariable sites of 0.90 ). The resulting tree was translated into a tree with maximum parsimony branch lengths.

Average pairwise distances between haplotypes (not considering the number of individuals sharing each haplotype and therefore giving all haplotypes the same weight) were calculated and used to estimate the timing of cladogenic events of the stone loach lineage in this area. We used a molecular clock rate of $1 \%$ substitutions per site per million year (Myr), which is commonly used for freshwater fish in Europe - and appears more appropriate than the alternative suggested estimate of $2 \%$ substitutions per site per Myr (Smith 1992; Nesbø et al. 1999; Englbrecht et al. 2000; Bernatchez 2001; Koskinen et al. 2002; Weiss et al. 2002; Salzburger et al. 2003).

A mismatch analysis was performed to study the demographic history of the species in the area (Fig. 2). The observed pairwise mismatch distribution (including the information about the number of individuals that share each haplotype) was fitted to a sudden demographic model by computing the raggedness index of the observed distribution (Harpending 1994) and by a generalized least square procedure as implemented in ARLEQUIN version 2.001 (Schneider et al. 2000). The validity of a stepwise expansion model for the data was tested by Markov chain Monte Carlo (MCMC) simulations (1000 steps) with ARLEQUIN. We computed the moment estimator of time to the expansion $(\tau)$, and the substitution parameters before $\left(\theta_{0}=2 \mu N_{0}\right)$ and after $\left(\theta_{1}=2 \mu N_{1}\right)$ expansion using a parametric bootstrap approach (1000 simulations), where $\mu$ is the mutation rate, and $N$ is the female effective population size. With the equation $\tau=2 \mu t$ we inferred a timescale for the demographic expansion of the population (where $t$ is the expansion time in generations), using an average generation time of 1 year (Breder \& Rosen 1966).

Genetic differences between seasons, years, and localities were estimated with pairwise F-statistics (Weir \& Cockerham 1984) as implemented in ARLEQUIN. To determine how genetic variation was partitioned, ARLEQUIN was used to estimate the hierarchical nesting of genetic diversity using the analysis of molecular variance (AMOVA) approach of Excoffier et al. (1992). The percentage of the total genetic variation within and among populations was calculated. To test for isolation by distance, correlations between geographical and genetic distances were calculated applying a Mantel test with ARLEQUIN. The control localities 12 and 13 were excluded from the latter analysis. Two types of geographical distances were defined: the matrix of the shortest distances between sample sites (thus, connections through deep water were possible), and the matrix of the shoreline distances (allowing exclusively connections through shallow areas).

Microsatellites. The basic descriptive statistics, number of alleles, expected heterozygosity $\left(H_{\mathrm{E}}\right)$ and observed heterozygosity $\left(H_{\mathrm{O}}\right)$, were compiled using ARLEQUIN. Departure from Hardy-Weinberg equilibrium (HWE) for each locus across and within populations was calculated using a test analogous to Fisher's exact tests (Guo \& Thompson 1992) estimated with a 100000 step, 1000 iteration, MCMC series of permutations, as implemented in ARLEQUIN. Linkage disequilibrium (LD) was tested using ARLEQUIN for all possible pairs of loci in each population and globally for each pair of loci across populations. Allelic richness was standardized to the smallest sample size using a rarefaction model as calculated in FSTAT (Goudet 1995). Differences between populations in (standardized) allelic richness was calculated with a Mann-Whitney $U$-test using STATISTICA (Stat Soft, Inc. 2003).

Genetic structure between seasons, years, and localities was analysed by Wright's F-statistics (Weir \& Cockerham 1984) based on differences in allele frequencies as implemented in ARLEQUIN. A hierarchical AMOVA was performed with ARLEQUIN to estimate how variation was partitioned within and among populations. Correlations between geographical and genetic distances were calculated with a Mantel test using ARLEQUIN (control localities were not included).

Critical significance levels for multiple testing were corrected following the sequential Bonferroni procedure (Rice 1989).

\section{Results}

\section{Species distribution}

The number of samples collected in the studied localities of Lake Constance during the different fishing campaigns is 
shown in Table 1. Stone loach was practically absent from two recently 'renaturalized' areas of the lake (sites 3 and 5; see Fig. 1a). The absence of stone loach in these newly available habitats might be explained by its limited capacity for dispersal and colonization. In contrast, a direct competitor for habitat of stone loach, the juveniles of the burbot, Lota lota (Pisces: Gadidae), which typically coexists with it in the shallow areas of the lake, and is characterized by large size and high mobility, was present in these areas in large numbers (personal observation). Both stone loach and burbot were virtually absent from a third locality (site 7, see Fig. 1a) characterized by a very steep littoral profile with only a narrow shallow terrace (personal observation). Therefore, the limited samples from sites 3, 5 and 7 were excluded, and only 10 of the 13 localities sampled were included in the analyses.

\section{Genetic diversity and demography inferred from mtDNA}

Fifty-six different mitochondrial haplotypes were found among the 435 sequences of stone loach included in this study. The haplotypes differed from each other by 1-40 mutations in the 1100-bp-long alignment of the mitochondrial control region. An insertion of $36 \mathrm{bp}$ was found between the positions 52-87 in haplotype 30 (Fig. 1b). A dinucleotide repeat was found between the positions 896-907 [(TA $)_{4}$ ] with an addition of a segment in haplotypes 43-51 [(TA) 5 ], and another segment added in haplotypes 50 and 51 [(TA $\left.)_{6}\right]$. An unrooted network tree which includes all haplotypes found in the lake is depicted in Fig. 1b. In the haplotype network, haplotype 25 was found as the most likely ancestral haplotype through which the most abundant haplotypes 16, 1, 38, and 53 are connected.

The average pairwise distance between haplotypes (the 36-bp insertion in haplotype 30 was excluded from this analysis) was $0.36 \%(\mathrm{SD}=0.21 \%)$, and the mean number of pairwise differences was $3.87(\mathrm{SD}=1.97)$. We applied a molecular clock to roughly estimate the age of the stone loach lineages in the studied area, although we recognize the potential problems and limits associated with a molecular clock approach (see e.g. Hillis \& Moritz 1995; Page \& Holmes 1998). Therefore, the divergence times obtained are presented here only as an approximation. We estimated a maximum age of the stone loach lineage in Lake Constance ranging from 150000 to 570000 years.

A mismatch analysis was performed to determine the recent demography of stone loach in Lake Constance (the 36-bp insertion in haplotype 30 was excluded from this analysis) (Fig. 2). A model of sudden demographic expansion was not supported neither by a generalized-least square procedure $(S \mathrm{SD}=0.005, P<0.001)$ nor by the raggedness index of the distribution (Rag. $=0.05, P<0.05$ ) indicating that much of the genetic differentiation observed appeared long before the invasion of the lake. The mean number of differences between haplotypes was 2.54. The moment estimator of time to the expansion $(\tau)$ was 2.48 (1.86-2.83) and the substitution parameters before $\left(\theta_{0}\right)$ and after $\left(\theta_{1}\right)$ expansion were 0.09 and 3446.95 , respectively. With the equation $\tau=2 \mu t$, where $\mu$ was assumed as $1 \%$ substitutions per site per Myr, we inferred that the timescale $(t)$ of the most important demographic expansion of this species in the area was between 100000 and 150000 generations ago (the average generation time for this species is 1 year; Breder \& Rosen 1966), which is older than the age of Lake Constance (c. 15000 years).

\section{Genetic diversity inferred from microsatellites}

We assayed microsatellite variation across 453 individuals at five microsatellite loci. The number of alleles observed across all populations ranged from eight (Bbar1) to 60 (Bbar8) with an average of 22.4 alleles per locus. The number of alleles per locus and population is compiled in Table 2. Expected heterozygosity averaged 0.80 across all loci and populations and ranged from 0.67 (Bbar1) to 0.97 (Bbar8). Observed and expected heterozygosities within populations are shown in Table 2. Unfortunately, no previous information about levels of polymorphism for these loci is available (see Taylor et al. 2001b) that could be compared with the present data. Significant deviations from HWE were found in all loci when the individuals from all populations were pooled, suggesting some subdivision among populations. Individual populations were mostly in HWE, and deviations were only found in three out of 50 comparisons (Table 2). Disequilibrium between pairs of loci was nonsignificant in every comparison $(P>0.05)$. Allelic richness was similar in all sampled localities (Mann-Whitney $U$-test; $P>0.05$ ).

\section{Population genetic structure, AMOVA and Mantel test}

All temporal comparisons between seasons and years were nonsignificant $(P>0.05)$, therefore all samples within localities were pooled for further analyses. We found pronounced genetic substructuring among stone loach populations from the littoral zone of Lake Constance based on both mtDNA sequences and microsatellites. $F_{\mathrm{ST}}$ estimates between pairs of populations were significant in most cases (78 out of 90 comparisons; Table 3) and mostly only comparisons between adjacent populations failed to find significant differences. Comparisons based on mtDNA were about an order of magnitude larger than estimates based on microsatellites. The highest pairwise differentiation was found as expected in the mtDNA comparisons of the most distant population (Austria) with the remaining localities. However, the sample from the second control population (Langenargen) did not show such a large differentiation. 
Table 2 Number of alleles, observed $\left(H_{\mathrm{O}}\right)$ and expected $\left(H_{\mathrm{E}}\right)$ heterozygosities at every microsatellite locus, and number of mitochondrial alleles for each population. The number of private alleles is given in parentheses

\begin{tabular}{|c|c|c|c|c|c|c|c|c|c|c|}
\hline Loci & 1 Meer & $2 \mathrm{Bir}$ & 4 Sipl & $6 \mathrm{Bod}$ & 8 Klaus & 9 Litz & 10 Uni & 11 Kon & 12 Lang & 13 Aut \\
\hline \multicolumn{11}{|l|}{ Bbar1 } \\
\hline No. of alleles & 6 & 6 & $5(1)$ & 4 & 4 & 5 & 6 & 5 & 5 & 4 \\
\hline$H_{\mathrm{O}}$ & 0.68 & 0.77 & 0.65 & 0.40 & 0.48 & 0.41 & $0.38^{*}$ & 0.44 & 0.71 & 0.70 \\
\hline$H_{\mathrm{E}}$ & 0.73 & 0.74 & 0.66 & 0.40 & 0.53 & 0.51 & 0.55 & 0.53 & 0.69 & 0.72 \\
\hline \multicolumn{11}{|l|}{ Bbar3 } \\
\hline No. of alleles & $11(1)$ & 12 & 7 & 12 & $13(1)$ & 8 & 12 & 10 & 12 & 3 \\
\hline$H_{\mathrm{O}}$ & $0.69^{*}$ & 0.74 & 0.74 & 0.71 & $0.63^{*}$ & 0.70 & 0.79 & 0.70 & 0.76 & 0.40 \\
\hline$H_{\mathrm{E}}$ & 0.80 & 0.80 & 0.73 & 0.84 & 0.81 & 0.72 & 0.82 & 0.77 & 0.80 & 0.68 \\
\hline \multicolumn{11}{|l|}{ Bbar4 } \\
\hline No. of alleles & 10 & 8 & 6 & 7 & 8 & 7 & 7 & 9 & $10(1)$ & 5 \\
\hline$H_{\mathrm{O}}$ & 0.74 & 0.75 & 0.85 & 0.91 & 0.76 & 0.85 & 0.63 & 0.76 & 0.76 & 0.40 \\
\hline$H_{\mathrm{E}}$ & 0.79 & 0.78 & 0.71 & 0.78 & 0.76 & 0.82 & 0.78 & 0.76 & 0.80 & 0.63 \\
\hline \multicolumn{11}{|l|}{ Bbar7 } \\
\hline No. of alleles & 8 & 11 & 7 & 6 & 11 & 6 & 9 & $10(1)$ & $9(1)$ & 6 \\
\hline$H_{\mathrm{O}}$ & 0.71 & 0.78 & 0.80 & 0.79 & 0.63 & 0.89 & 0.77 & 0.59 & 0.67 & 0.90 \\
\hline $\begin{array}{r}H_{\mathrm{E}} \\
\text { Bbar8 }\end{array}$ & 0.70 & 0.75 & 0.85 & 0.77 & 0.71 & 0.80 & 0.75 & 0.75 & 0.72 & 0.81 \\
\hline No. of alleles & 40 & $45(1)$ & $21(1)$ & 29 & 24 & $32(1)$ & 33 & $37(1)$ & $47(5)$ & $12(1)$ \\
\hline$H_{\mathrm{O}}$ & 0.95 & 0.94 & 0.94 & 0.85 & 0.97 & 0.93 & 0.93 & 0.93 & 0.99 & 0.67 \\
\hline$H_{\mathrm{E}}$ & 0.97 & 0.97 & 0.92 & 0.96 & 0.96 & 0.98 & 0.97 & 0.96 & 0.97 & 0.93 \\
\hline mtHaplotypes & 16 & $21(6)$ & 6 & $11(2)$ & 8 & 8 & $13(2)$ & $14(5)$ & $25(11)$ & $6(3)$ \\
\hline
\end{tabular}

*Indicates loci with a significant deviation from Hardy Weinberg equilibrium after Bonferroni sequential correction.

Table 3 Estimate of pairwise comparisons of mtDNA haplotypes $\left(F_{\mathrm{ST}}\right.$ below the diagonal) and five microsatellite loci $\left(F_{\mathrm{ST}}\right.$ above the diagonal) of the stone loach populations across all geographical localities.

\begin{tabular}{|c|c|c|c|c|c|c|c|c|c|c|}
\hline & 1 Meer & 2 Bir & 4 Sipl & $6 \mathrm{Bod}$ & 8 Klaus & 9 Litz & 10 Uni & 11 Kon & 12 Lang & 13 Aut \\
\hline Meer & 0.00 & $0.00^{\mathrm{ns}}$ & $0.06^{* *}$ & $0.05^{* *}$ & $0.03^{* *}$ & $0.08^{* *}$ & $0.03^{* *}$ & $0.04^{* *}$ & $0.02^{* *}$ & $0.09^{* *}$ \\
\hline Bir & $0.04^{* *}$ & 0.00 & $0.06^{* *}$ & $0.05^{\star *}$ & $0.04^{* *}$ & $0.07^{* *}$ & $0.03^{* *}$ & $0.03^{* *}$ & $0.02^{* *}$ & $0.08^{* *}$ \\
\hline Sipl & $0.06^{* *}$ & $0.10^{* *}$ & 0.00 & $0.06^{* *}$ & $0.05^{* *}$ & $0.06^{* *}$ & $0.04^{* *}$ & $0.05^{* *}$ & $0.03^{* *}$ & $0.07^{* *}$ \\
\hline Bod & $0.20^{* *}$ & $0.21^{* *}$ & $0.14^{* *}$ & 0.00 & $0.01^{* *}$ & $0.03^{* *}$ & $0.01^{\mathrm{ns}}$ & $0.03^{* *}$ & $0.03^{* *}$ & $0.11^{* *}$ \\
\hline Klaus & $0.27^{* *}$ & $0.22^{* *}$ & $0.15^{* *}$ & $0.02^{\mathrm{ns}}$ & 0.00 & $0.05^{* *}$ & $0.00^{\mathrm{ns}}$ & $0.01^{*}$ & $0.01^{* *}$ & $0.07^{* *}$ \\
\hline Litz & $0.20^{* *}$ & $0.18^{* *}$ & $0.13^{* *}$ & $0.00^{\mathrm{ns}}$ & $0.00^{\mathrm{ns}}$ & 0.00 & $0.03^{* *}$ & $0.05^{* *}$ & $0.03^{* *}$ & $0.07^{* *}$ \\
\hline Uni & $0.31^{* *}$ & $0.27^{* *}$ & $0.18^{* *}$ & $0.05^{*}$ & $0.00^{\mathrm{ns}}$ & $0.00_{\mathrm{ns}}$ & 0.00 & $0.01^{\mathrm{ns}}$ & $0.01^{*}$ & $0.06^{* *}$ \\
\hline Kon & $0.52^{* *}$ & $0.45^{\star *}$ & $0.33^{* *}$ & $0.13^{* *}$ & $0.02^{\mathrm{ns}}$ & $0.06^{*}$ & $0.01^{\mathrm{ns}}$ & 0.00 & $0.02^{* *}$ & $0.05^{* *}$ \\
\hline Lang & $0.02^{* *}$ & $0.07^{*}$ & $0.02^{\mathrm{ns}}$ & $0.09^{* *}$ & $0.11^{* *}$ & $0.08^{* *}$ & $0.16^{* *}$ & $0.31^{* *}$ & 0.00 & $0.05^{* *}$ \\
\hline Aut & $0.51^{* *}$ & $0.35^{* *}$ & $0.32^{* *}$ & $0.78^{* *}$ & $0.74^{* *}$ & $0.77^{* *}$ & $0.69^{* *}$ & $0.88^{* *}$ & $0.45^{* *}$ & 0.00 \\
\hline
\end{tabular}

$F_{\mathrm{ST}}$ values have been linearized following Slatkin correction (Slatkin 1995). Probability values: ${ }^{*}<<0.05,{ }^{* *} P<0.001$, ns, nonsignificant.

Based on mitochondrial data, the proportion of the total molecular variance attributable to differences between populations was 15\%, which was significantly different from zero $(P<0.001)$. By contrast, little microsatellite variation was found between populations, explaining only $3 \%$ of the total variation, although still significantly different from zero $(P<0.001)$.

As suggested by its life history, a pattern of isolation by distance is strongly supported by these data for the stone loach. A highly significant correlation was found between genetic differentiation and geographical distance of populations along the shoreline of Lake Überlingen based on mtDNA sequences $(r=0.8829, P<0.001$; Fig. 3). However, the correlation between shoreline geographical distances and genetic differences measured with microsatellites was not as strong, although we detected a marked tendency for it $(r=0.2980, P<0.076)$. No correlation was found when genetic differentiation was compared with the shortest distances between populations connected by areas of deep water (mtDNA: $r=0.0376, P=0.386$; microsatellites: $r=0.0204$, $P=0.458)$. 


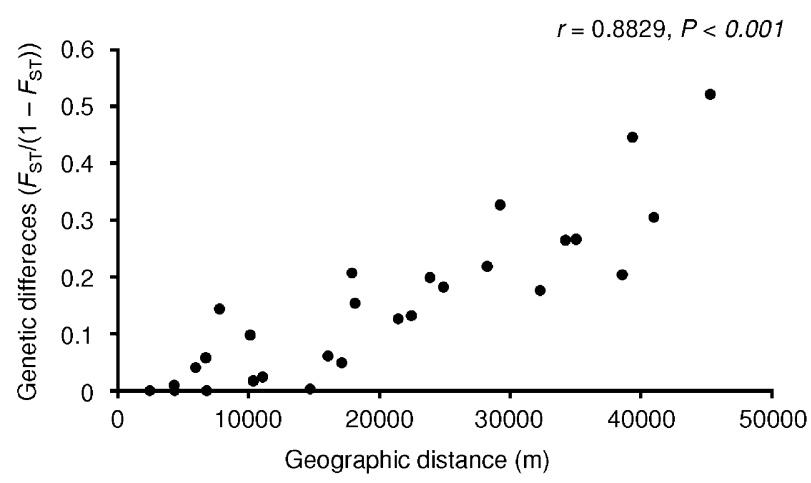

Fig. 3 Correlation between genetic differences (mtDNA; linearized $F_{\mathrm{ST}}$ values [(Slatkin 1995): $F_{\mathrm{ST}} /\left(1-F_{\mathrm{ST}}\right)$ ] and geographical distances (m) following the shoreline of Lake Constance (no connections through open water are allowed). $r$ represents the correlation coefficient and $P$ the probability value.

\section{Discussion}

\section{Colonization history of stone loach in Lake Constance}

The stone loach in Lake Constance has an unexpectedly high genetic diversity that contrasts with the young age of the lake itself. The lake bed of Lake Constance was formed by the Rhine glacier during glacial periods and could only be colonized by fish after the retreat of the most recent glacier around $15000 \mathrm{BP}$. The genetic diversity of stone loach populations in the area could have evolved in situ in the lake in this short period of time, but a more plausible explanation is that these lineages of stone loach were already genetically differentiated before the colonization of the lake. Although the application of a molecular clock for the estimation of divergence times may be problematic (see e.g. Hillis \& Moritz 1995; Page \& Holmes 1998) we used this approach to evaluate the two alternative hypotheses of the origin of the genetic diversity of stone loach. Assuming a mutation rate of $1 \%$ (substitutions per site per Myr), we estimated that the major expansion of this lineage happened around $132000 \mathrm{BP}$, a date that predates the formation of Lake Constance by about an order of magnitude, and approximately corresponds to the last interglacial maximum (Dawson 1992; Hewitt 1999). These data support the genetic differentiation of stone loach prior to the colonization of Lake Constance. The area surrounding the lake was covered with ice for c. 100000 years before its formation (Dawson 1992). Therefore, it is surprising that the stone loach populations in Lake Constance are genetically so differentiated. The marked stenotopy of stone loach renders it unlikely that a colonization of the area occurred from a geographically distant population since the last glaciation. Thus, stone loach populations might have survived in refugia in permafrost regions of Europe during the last glacial period. Several refugia might have existed in the area, which enlarge the overall diversity. Populations probably dispersed geographically gradually along ice-free rivers or temporal pro-glacial lakes from glacial refugia to their present habitats. Our data suggest that no major fragmentation of populations or genetic bottlenecks affected this species in the area during this time.

In addition, applying the same molecular clock calibration (1\%), we estimated that the maximum age of the stone loach lineage inhabiting Lake Constance is older than the putative main expansion (c. 360000 years). Therefore, this lineage might be relatively old, probably originated elsewhere (with one or several origins) and only rather recently, after the last interglacial event, successfully colonized the area of Lake Constance. The estimated maximum age of the stone loach in Lake Constance approximately corresponds to the time of expansion of other fish lineages associated with the Danube and Rhine rivers (Danube lineage of brown trout, Bernatchez 2001; mixed Rhine/ Danube lineage of grayling, Weiss et al. 2000; Danube/ Rhine lineage of vairone, Salzburger et al. 2003), therefore fitting in the overall phylogeographical scenario of central Europe. Future sampling of stone loach from both the Danube and the Rhine rivers - main refugia for many freshwater fish species in the Alpine area (e.g. Nesbø et al. 1999; Weiss et al. 2002) - might reveal the genetic affiliation of the stone loach lineages in Lake Constance to populations from those basins.

High levels of genetic diversity, similar to the case of stone loach in Lake Constance, have been reported for at least two other fish species from central Europe: vairone, Leuciscus souffia (Salzburger et al. 2003) and bullhead, Cottus gobio (Englbrecht et al. 2000; Knapen et al. 2003; Knaepkens et al. 2004). These three species, stone loach, vairone, and bullhead, coexist sympatrically in central European rivers, sharing the similar environmental preferences, such as cold water, stony substrates, and intolerance to low oxygen levels. Interestingly, they are all poor dispersers, and the argumentation that they maintain large genetic diversity in central Europe because they have survived in refugia within the permafrost regions of Europe during the last glacial period might apply to all of them.

The described situation in stone loach contrasts with the relatively low genetic diversity of some other freshwater fish species in central Europe, like brown trout (Bernatchez 2001), burbot (Van Houdt 2003; Van Houdt et al. 2003; Barluenga \& Meyer unpublished), chub (Durand et al. 1999), or Eurasian perch (Nesbø et al. 1999; BehrmannGodel et al. 2004). Englbrecht et al. (2000) suggested that many of these species might have been almost completely eradicated from central and western Europe during the major glaciations, and one or a few refugial lineages have just recently recolonized this area. It seems clear that each species responded individually to the ice age and subsequent 
warming, based on their particular set of environmental conditions (Hewitt 1999). Large-scale comparative population genetic studies of freshwater fish of central Europe would provide a comprehensive view of the genetic consequences of the last glaciation events on species with different life histories, and their effect on the current genetic diversity and geographical distribution patterns.

\section{Barriers to dispersal and isolation by distance}

Populations of stone loach from the littoral zone of Lake Constance were found to be differentiated on the basis of two types of neutral molecular markers - mtDNA sequences and microsatellite loci (Table 3). Both molecular markers showed consistent results. However, microsatellites population differentiation measures were about an order of magnitude lower than those of mitochondrial sequences. The relatively low number of microsatellite loci used (5) might be one cause of the poor resolution (see e.g. Koskinen et al. 2004). An alternative explanation might be that the high polymorphism of microsatellite loci is likely to underestimate genetic divergence between populations, as proposed by Hedrick (1999). Microsatellites often have very high within-population heterozygosity, thereby reducing the maximum possible differentiation values $\left(F_{\mathrm{ST}}\right)$ (Hedrick 1999).

Two alternative hypotheses could explain the genetic differences of fish from different locations in the lake: (i) Lake Constance was colonized by a large heterogeneous lineage of stone loach that differentiated in several rather isolated groups in diverse areas of the lake; or (ii) the lake was colonized by multiple genetically diverse lineages of stone loach from different refugia that posteriorly homogenized in the lake. The clear pattern of isolation by distance observed, i.e. increase of genetic differences with geographical distance (Wright 1943), is more in accordance with the first hypothesis, as well as with stone loach life history, philopatry, and limited capacity for dispersal. Geographic distances - not allowing for connections through open water - are the best explanation for the observed geographical distribution of genetic variation between populations. Shoreline distances between populations explain $78 \%$ of the genetic variance in the mtDNA comparisons but only $0.09 \%$ of the genetic variance in microsatellite analyses $(r 2)$. The poor correlation between geographical distances and nuclear genetic markers is not surprising in a population with such recent history since diploid markers go to fixation more slowly than haploid mitochondrial markers.

It seems clear that the open water represents a barrier for the dispersal of stone loach, and therefore, stone loach pioneers most likely followed the shoreline when they initially colonized the lake. Colonization must have occurred in a stepwise manner and, after the initial settlement, stone loach populations must have remained at least partially isolated to explain the current large genetic differences among them. The future collection of detailed bathymetric and substrate information (e.g. habitat discontinuities) might reveal which limnological parameters act as barriers to gene flow in this species. Our data suggest that distance alone might be sufficient to explain a significant portion of the observed genetic structure between the sampled populations. Substrate discontinuities and seasonal fluctuation of the level of the lake might influence the accessibility of some environments impacting the distribution and dispersal of populations.

In summary, the last postglacial colonization of Lake Constance by stone loach is likely to have originated by a rather large and heterogeneous lineage that followed a stepping-stone dispersal mode where migration occurred only between adjacent shoreline patches. Gene flow among the studied stone loach populations is very low and distance appears as the main isolating factor. The high stability of genetic populations over seasons and years (10\% recapture rate; personal observation) supports this idea as well. Stone loach is an obligate littoral species in lacustrine environments unable to disperse across areas of deep water, a common phenomenon among littoral zone fish (e.g. Markert et al. 1999). High oxygen requirements might act additionally as a physiological constraint preventing the vertical migration of stone loach.

Extremely fine-scale genetic population structure appears to be a general phenomenon common to poor dispersing fish species and guilds that are highly specialized on particular substrates finely partitioning the environment (Douglas et al. 1999; Reusch et al. 2001; Rogers et al. 2002), and isolation-by-distance scenarios are common outcomes (e.g. Arnegard et al. 1999; Wang et al. 2000; Koskinen et al. 2001; Reusch et al. 2001; Taylor et al. 2001a).

In temperate fish, examples of strongly structured populations exist, although studies on an extreme geographical fine scale are not common. Some studies report cases of isolation by distance in fish lineages inhabiting different streams (e.g. Wenburg et al. 1998; Wang et al. 2000), or lineages inhabiting streams or lakes (e.g. Hendry et al. 2002), but studies on the geographical genetic structures in continuous habitats are rare. One of the few exceptions is the exhaustive study by Castric \& Bernatchez (2003) on the population genetic structure of the brook charr, a coastal fish endemic to northeastern North America, along its entire geographical range. Repeated instances of isolation by distance are reported in successive dispersal waves, and the restricted coastal distribution together with the loss of dispersal capabilities associated with anadromy is proposed as the main causes of the structuring.

In contrast to benthic fish with restricted dispersal, pelagic fish often comprise panmictic populations with no apparent barriers to migration, and therefore, little 
opportunity for isolation and genetic divergence. For example, in Lake Constance, the burbot (with pelagic adults but benthic juveniles), which is characterized by the yearly migration to common spawning areas within the lake, might comprise one single panmictic population (Barluenga \& Meyer, unpublished). Shaw et al. (2000) demonstrated a similar trend in at least 3 of the 21 described pelagic cichlid fish from Lake Malawi. They found that these species had lake-wide distributions and formed single panmictic units across the lake. They suggest that along the 500-km long Lake Malawi, the habitats for these species would remain homogeneous favouring the uniformity of the populations. In conclusion, while pelagic habits generally seem to prevent genetic divergence in allopatry, benthic bottom dwelling habits appear to promote isolation and differentiation of fish populations.

\section{Evolutionary implications of life histories}

High levels of substructuring between adjacent populations might be expected to facilitate speciation. Particularly in small isolated populations, drift, adaptation to local conditions or sexual selection will have important effects on gene frequencies. Therefore, one would expect that species with poor dispersal capabilities and high levels of substructuring exhibit high levels of intraspecific variation in some traits (e.g. Van Oppen et al. 1997). This appears, however, not to be the case for stone loach, where no appreciable variation in morphological, physiological, or behavioural traits has been detected so far. Similar discordances between morphological and genetic differences have been documented in other fish groups (e.g. Shaw et al. 2000; Wang et al. 2000; Taylor \& Verheyen 2001). Therefore, high levels of genetic substructuring alone do not seem to be sufficient to promote high levels of speciation. This suggests that other species-specific factors might influence whether groups speciate or not, such as breeding behaviour (Mayr 1984).

\section{Acknowledgements}

We thank H. Fischer, E. Hespeler, A. Sulger and A. Zahn for assistance in the field and A. Markl and U. Topel for assistance in the laboratory. Beat Grabherr provided the samples from Austria. We also thank Walter Salzburger, Matthias Sanetra and Philipp Fischer for a very useful discussion. This study was supported by Deutsche Forschungsgemeinschaft through the Collaborative Research Centre grant (SFB 454) 'Littoral of Lake Constance' to MB and AM, and by Consejería de Educación y Cultura del Principado de Asturias, Plan de Investigación Desarrollo Tecnológico e Innovación de Asturias 2001-04 to MB.

\section{References}

Arnegard ME, Markert J, Danley PD, Stauffer JR, Ambali AJ, Kocher TD (1999) Population structure and colour variation of the cichlid fish Labeotropheus fuelleborni Ahl along a recently formed archipelago of rocky habitat patches in southern Lake Malawi. Proceedings of the Royal Society of London. Series B, Biological Sciences, 266, 119-130.

Behrmann-Godel J, Gerlach G, Eckmann R (2004) Postglacial colonization shows evidence for sympatric population splitting of Eurasian perch (Perca fluvialitis L.) in Lake Constance. Molecular Ecology, 13, 491-497.

Bernatchez L (2001) The evolutionary history of brown trout (Salmo trutta L.) inferred from phylogeographic, nested clade, and mismatch analyses of mitochondrial DNA variation. Evolution, 55, 351-379.

Breder CM, Rosen DE (1966) Modes of Reproduction in Fishes. T.F.H. Publications, Neptune City, New Jersey

Bruford MW, Hanotte O, Brookfield JFY, Burke T (1998) Multi-locus and single-locus DNA fingerprinting. In: Molecular Genetic Analysis of Populations (ed. Hoelzel AR), pp. 283-336. Oxford University Press, New York.

Brunner PC, Douglas MR, Bernatchez L (1998) Microsatellite and mitochondrial DNA assessment of population structure and stocking effects in Arctic charr Salvelinus alpinus (Teleostei: Salmonidae) from Central Alpine lakes. Molecular Ecology, 7, 209-223.

Castric V, Bernatchez L (2003) The rise and fall of isolation by distance in the anadromous brook charr (Salvelinus fontinalis Mitchill). Genetics, 163, 983-996.

Dawson AG (1992) Ice Age Earth. Routledge Press, London.

Douglas MR, Brunner PC, Bernatchez L (1999) Do assemblages of Coregonus (Teleostei: Salmoniformes) in the Central Alpine region of Europe represent species flocks? Molecular Ecology, 8, 589-603.

Durand JD, Persat H, Bouvet Y (1999) Phylogeography and postglacial dispersion of the chub (Leuciscus cephalus) in Europe. Molecular Ecology, 8, 989-997.

Englbrecht CC, Freyhof J, Nolte A, Rassmann K, Schliewen U, Tautz, D (2000) Phylogeography of the bullhead Cottus gobio (Pisces: Teleostei: Cottidae) suggests a pre-Pleistocene origin of the major central European populations. Molecular Ecology, 9, 709-722.

Excoffier L, Smouse P, Quattro J (1992) Analysis of molecular variance inferred from metric distances among DNA haplotypes: Application to human mitochondrial DNA restriction data. Genetics, 137, 479-491.

Fischer P, Eckmann R (1997a) Seasonal changes in fish abundance, biomass and species richness in the littoral zone of a large European lake, Lake Constance, Germany. Archiv für Hydrobiologie, 139, 433-448.

Fischer P, Eckmann R (1997b) Spatial distribution of littoral fish species in a large European lake, Lake Constance, Germany. Archiv für Hydrobiologie, 140, 891-116.

Garant D, Dodson JJ, Bernatchez L (2000) Ecological determinants and temporal stability of the within-river population structure in Atlantic salmon (Salmo salar L.). Molecular Ecology, 9, 615628.

Gerlach G, Schardt U, Eckmann R, Meyer A (2001) Kin-structured subpopulations in Eurasian perch (Perca fluviatilis L.). Heredity, 86, 213-221.

Goudet J (1995) FSTAT, Version 1.2: a computer program to calculate F-statistics. Journal of Heredity, 86, 485-486.

Guo SW, Thompson EA (1992) Performing the exact test of Hardy-Weinberg proportion of multiple alleles. Biometrics, 48, 361-372. 
Harpending RC (1994) Signature of ancient population growth in a low-resolution mitochondrial DNA mismatch distribution. Human Biology, 66, 591-600.

Hedrick PW (1999) Highly variable loci and their interpretation in evolution and conservation. Evolution, 53, 313-318.

Hendry AP, Taylor EB, McPhail JD (2002) Adaptive divergence and the balance between selection and gene flow: lake and stream stickleback in the misty system. Evolution, 56, 11991216.

Hewitt GM (1999) Postglacial recolonization of European biota. Biological Journal of the Linnean Society, 68, 87-112.

Hillis DM, Moritz C (1995) Molecular Systematics. Sinauer Associates, Sunderland, Massachusetts.

Huelsenbeck JP, Crandall KA (1997) Phylogeny estimation and hypothesis testing using maximum likelihood. Annual Review of Ecology and Systematics, 28, 437-466.

Johnson ML, Gaines MS (1990) Evolution of dispersal: theoretical models and empirical tests using birds and mammals. Annual Review of Ecology and Systematics, 21, 449-480.

Knaepkens G, Bervoets L, Verheyen E, Eens M (2004) Relationship between population size and genetic diversity in endangered populations of the European bullhead (Cottus gobio): implications for conservation. Biological Conservation, 115, 403-410.

Knapen D, Knaepkens G, Bervoets L, Taylor MI, Eens M, Verheyen $\mathrm{E}$ (2003) Conservation units based on mitochondrial and nuclear DNA variation among European bullhead populations (Cottus gobio L., 1758) from Flanders, Belgium. Conservation Genetics, 4, 129-140.

Kocher TD, Thomas WK, Meyer A et al. (1989) Dynamics of mitochondrial DNA evolution in animals: amplification and sequencing with conserved primers. Proceedings of the National Academy of Sciences of the United States of America, 86, 61966200.

Koskinen MT, Piironen J, Primmer CR (2001) Interpopulation genetic divergence in European grayling (Thymallus thymallus, Salmonidae) at a microgeographic scale: implications for conservation. Conservation Genetics, 2, 133-143.

Koskinen MT, Hirvonen H, Landry P-A, Primmer CR (2004) The benefits of increasing the number of microsatellites utilized in genetic population studies: an empirical perspective. Hereditas, 141, 61-67.

Koskinen MT, Knizhin I, Primmer CR, Schlötterer C, Weiss S (2002) Mitochondrial and nuclear DNA phylogeography of Thymallus spp. (grayling) provides evidence of ice-age mediated environmental perturbations in the world's oldest body of fresh water, Lake Baikal. Molecular Ecology, 11, 2599-2611.

Markert JA, Arnegard ME, Danley D, Kocher TD (1999) Biogeography and population genetics of the Lake Malawi cichlid Melanochromis auratus: habitat transience, philopatry and speciation. Molecular Ecology, 8, 1013-1026.

Mayr E (1984) Evolution of fish species flocks: a commentary. In: Evolution of Fish Species Flocks (eds Echelle AA, Kornfield IRV), pp. 3-11. University of Maine at Orono Press, Orono, Maine.

Meyer A, Morrissey JM, Schartl M (1994) Recurrent origin of a sexually selected trait in Xiphophorus fishes inferred from a molecular phylogeny. Nature, 368, 539-542.

Mills CA, Welton JS, Rendle EL (1983) The age, growth and reproduction of the stone loach Noemacheilus barbatula (L.) in a Dorset chalk stream. Freshwater Biology, 13, 283-292.

Muus BJ, Dahlström P (1968) Süsswasserfische. BLV Verlagsgesellschaft, München, Germany.

Nesbø CL, Fossheim T, Vøllestad LA, Jakobsen KS (1999)
Genetic divergence and phylogeographic relationships among European perch (Perca fluviatilis) populations reflect glacial refugia and postglacial colonization. Molecular Ecology, 8, 13871404.

Page DM, Holmes EC (1998) Molecular Evolution: A Phylogenetic Approach. Blackwell Sciences, Oxford.

Posada D (1999) COLLAPSE, Version 1.1. Department of Zoology, Brigham, Young University.

Posada D, Crandall KA (1998) modeltest: testing the model of DNA substitution. Bioinformatics, 14, 817-818.

Reusch TB, Wegner KM, Kalbe M (2001) Rapid genetic divergence in postglacial populations of threespine sitckleback (Gasterosteus aculeatus): the role of habitat type, drainage and geographical proximity. Molecular Ecology, 10, 2435-2445.

Rice WR (1989) Analyzing tables of statistical tests. Evolution, 43, 223-225.

Rico C, Turner GF (2002) Extreme microallopatric divergence in a cichlid species from Lake Malawi. Molecular Ecology, 11, 15851590.

Rogers SM, Gagnon V, Bernatchez L (2002) Genetically based phenotype-environment association for swimming behavior in lake whitefish ecotypes (Coregonus clupeaformis Mitchill). Evolution, 56, 2322-2329.

Salzburger W, Branstätter A, Gilles A et al. (2003) Phylogeography of the vairone (Leuciscus souffia, Risso 1826) in central Europe. Molecular Ecology, 12, 2371-2386.

Schneider S, Roessli D, Excoffier L (2000) ARLEQUIN, Version 2.001: a software for genetic data analysis. Genetics and Biometry Laboratory. University of Geneva, Geneva, Switzerland.

Shaw PW, Turner GF, Idid MR, Robinson RL, Carvalho GR (2000) Genetic population structure indicates sympatric speciation of Lake Malawi pelagic cichlids. Proceedings of the Royal Society of London. Series B, Biological Sciences, 267, 2273-2280.

Slatkin M (1995) A measure of population subdivision based on microsatellite allele frequencies. Genetics, 139, 457-462.

Smith GR (1992) Introgression in fishes: significance for paleontology, cladistics, and evolutionary rates. Systematic Biology, 41, 41-57.

Smyly WJP (1955) On the biology of the stone loach Noemacheilus barbatula (L.). Journal of Animal Ecology, 24, 167-186.

Stat Soft Inc. (2003) statistica for Windows, Version 6. www.statsoft.com.

Swofford DL (2002) PAUP*: Phylogenetic Analysis Using Parsimony ("and Other Methods). Sinauer Associates, Sunderland, Massachusetts.

Taylor MI, Verheyen E (2001) Microsatellite data reveals weak population substructuring in Copadichromis sp. 'virginalis kajose', a demersal cichlid from Lake Malawi, Africa. Journal of Fish Biology, 59, 593-604.

Taylor MI, Blust R, Verheyen E (2001b) Characterization of microsatellite loci in the stone loach, Barbatula barbatula L. Molecular Ecology Notes, 1, 96-97.

Taylor MI, Rüber L, Verheyen E (2001a) Microsatellites reveal high levels of population substructuring in the species-poor Eretmodine cichlid lineage from Lake Tanganyika. Proceedings of the Royal Society of London. Series B, Biological Sciences, 268, 803-808.

Van Houdt J (2003) A mitogenic view on the origin and evolutionary history of the only freshwater gadoid (burbot, Lota lota). PhD thesis, Catholic University of Leuven, Leuven Belgium.

Van Houdt J, Hellemans B, Volckaert FAM (2003) Phylogenetic relationships among Palearctic and Nearctic burbot (Lota lota): 
Pleistocene extinctions and recolonization. Molecular Phylogenetics and Evolution, 29, 599-612.

Van Oppen MJ, Turner GF et al. (1997) Unusually fine-scale genetic structuring found in rapidly speciating Malawi cichlid fishes. Proceedings of the Royal Society of London. Series B, Biological Sciences, 264, 1803-1812.

Wang JP, Hsu KC, Chiang TY (2000) Mitochondrial DNA phylogeography of Acrossocheilus paradoxus (Cyprinidae) in Taiwan. Molecular Ecology, 9, 1483-1494.

Weir BS, Cockerham CC (1984) Estimating F-statistics for the analysis of population structure. Evolution, 38, 1358-1370.

Weiss S, Antunes A, Schlötterer C, Alexandrino P (2000) Mitochondrial haplotype diversity among Portuguese brown trout Salmo trutta L. populations: relevance to the post-Pleistocene recolonization of northern Europe. Molecular Ecology, 9, 691-698.

Weiss S, Persat H, Eppe R, Schlötterer CU, Iblein F (2002) Complex patterns of colonization and refugia revealed by for European grayling Thymallus thymallus, based on complete sequencing of the mitochondrial DNA control region. Molecular Ecology, 11, 1393-1407.

Wenburg JK, Bentzen P, Foote CJ (1998) Microsatellite analysis of genetic population structure in an endangered salmonid: the coastal cutthroat trout (Oncorhynchus clarki clarki). Molecular Ecology, 7, 733-749.

Wheeler A (1992) Freshwater Fishes of Britain and Europe. Rinbow Books, Elsley House, London, UK.

Wirth T, Bernatchez L (2001) Genetic evidence against panmixia in the European eel. Nature, 409, 1037-1040.

Wright S (1943) Isolation by distance. Genetics, 28, 114-138.

Marta Barluenga is postdoctoral fellow interested in speciation and the origin of adaptive radiations. Axel Meyer is an evolutionary geneticist interested in the ecological, developmental and genomic aspects of speciation. 